\title{
A Comparison between Two Balanced Scorecards: Optimal vs. Kaplan and Norton Model
}

\author{
Bernard Morard, Alexandru Stancu, Senior Member, IEDRC, and Christophe Jeannette
}

\begin{abstract}
This paper compares two Balanced Scorecard models, an optimal construction based on a time-managed approach to identify the evolution of the key contributors to the current organization's strategy and a model based on Kaplan and Norton methodology. Both Balanced Scorecards are generated using financial and non-financial strategic indicators collected directly from the company. The paper proposes a process to construct an optimal structure of a Balanced Scorecard model based on the Partial Least Square equations. The optimal model is based on a modified version of bootstrap technique that seeks and chooses the most predictable cause-and-effect sequence among all possible combinations. The Kaplan's model is grounded on the authors' methodology as presented in their articles and books. The comparison between the two models will be analyzed and validated using a practical example from a Swiss medical establishment. It will be concluded that the Optimal Balanced Scorecard (OBSC) is superior to the Kaplan's model in terms of statistical validation and, thus, OBSC advantage to accurately represent and study the company's strategy.
\end{abstract}

Index Terms-Balanced scorecard (BSC), key performance indicators, performance measurement, structural equation modeling (SEM), partial least squares (PLS), principal component analysis (PCA), bootstrap.

\section{INTRODUCTION}

In the early 1990s, Robert Kaplan and David Norton introduced a novel approach to strategic management, called the Balanced Scorecard (BSC). Identifying some of the weaknesses and ambiguities of previous management systems, the BSC method offers a comprehensive direction as to what companies should concentrate on in order to "balance" the financial perspective with other critical areas. One of the main advantages of the BSC and one of the main peculiarities from other methodologies is that the model has the ability to articulate a complex chain of cause-and-effect within the organization. This pattern offers executives a framework to handle the drivers of needed results and, therefore, the cause-and-effect chain is essential to the BSC. Kaplan and Norton (1996) assume the following basic relationship: the measures of organizational learning and growth will influence the measures of internal business processes, which will affect the measures of the customer perspective, which, in turn, will alter the financial measures [1], [2].

Nevertheless, one of the of the BSC weaknesses lies in its rationalization and construction. Despite the fact that the two

Manuscript received October 16, 2013; revised November 27, 2013.

Bernard Morard, Christophe Jeannette, and Alexandru Stancu are with the HEC Department (Haute Ecole Commerciale), University of Geneva, 1205 Geneva, Switzerland (e-mail: bernard.morard@unige.ch, stancua@iata.org, christophe.jeannette@unige.ch). authors offer some fundamental elements and describe the steps for building the BSC, the concepts remain ambiguous and can be difficult to effectively apply in a company [3].

There are three main goals in this paper. The first objective is to overcome the above limitations and present a framework for a rational construction of an Optimal BSC (OBSC) using the Partial Least Square (PLS) technique and by establishing the optimal cause-and-effect chain in order to forecast the future changes in organization's performance. The OBSC framework will be exemplified and validated using a real example from a Swiss hospital. The second goal is an attempt to build a Kaplan \& Norton's BSC using the same data and based on the original concepts developed by the authors. The third and final objective of this study is to compare the two models, both from a strategic perspective and from a statistical point of view. It will be noted that, not only the OBSC is closer to the actual strategy of the company, but our optimal model is also more stable and with higher statistical significance than the Kaplan and Norton's counterpart.

The paper is structured as follows. In the next section, we will present high-level the main BSC concepts from the specialized literature. We will stress the "idealistic" process of 4-axes construction followed by a more rational framework allowing for the identification of the number of strategic perspectives as well as the performance indicators connected to each perspective. We will set forth a tentative modeling of OBSC that can be implemented in any company. The framework is validated with a real example of a Swiss medical establishment using a modified version of the bootstrap technique to propose an alternative quality criterion that seeks and selects the most reliable cause-and-effect sequence among all possible combinations. Using the same data from the Swiss organization, we will build, in parallel, a Kaplan and Norton's BSC using a more rigid approach when selecting the indicators for strategic perspectives. Finally we will confront the two models and we will pose the final conclusions and remarks.

\section{LITERATURE REVIEW}

\section{A. Balanced Scorecard}

As recorded by Fielden [4], worldwide organizations use the ability of BSC for converting vision and strategy into measurable objectives. Several studies estimate that 60 percent of Fortune 1000 companies have worked with the BSC [5]. Another study published in 2011 written by B. McDonald covering the years 1991 to 2011 in the medical sector concludes that 6300 documents (conference, articles) containing the words "balanced scorecard and healthcare" was written during the same period [6].

The BSC identifies the cause-and-effect relations between 
the various components of an organization [7]. From a practical viewpoint, this is the main element of the BSC, grouping outcome metrics and performance drivers, connected together in a cause-and-effect chain. In reality, this postulate is the essence of the model, allowing measures in non-financial areas to be used to predict future financial performance [8].

Nevertheless, the BSC also has several shortcomings with some of its main assumptions and relations underlined by numerous authors from the specialized literature. Nørreklit [9] states that there is not a causal but rather a logical relationship between the strategic perspectives analyzed. Moreover, the $\mathrm{BSC}$ is not a representative strategic management tool because it does not consider any connection between the organizational and actual environment the organization is functioning in (e.g. competition). Consequently, a discrepancy should be admitted between the strategy emerging from the actions and the assumed strategy [9].

Kanji (2002) summarizes more BSC downsides emphasizing that the model [10] is overly abstract and not user-friendly as a measurement model. Furthermore, the relations between criteria are not clearly explained and, finally, the causal relationships are problematic (more like interdependence, rather than correlations).

Lastly, Malina \& Selto [11] asserts that the BSC is very difficult to put into practice. The authors underline several negative aspects of the BSC and present significant controversy between the organization and its stakeholders. They also determined that the performance indicators employed in the model are biased or inaccurate, the communication about the BSC within a company is strictly top-down and the comparisons between companies are inappropriate, even though these benchmarks are widely used for assessments.

\section{B. Partial Least Squares (PLS)}

Within this extensive environment of uncertainty and criticism, some authors [3], [12]-[14] have invited management accounting researchers to make better use of Structural Equation Modeling (SEM). SEM is a statistical method comprising Path Modeling, Partial Least Squares (PLS) and latent variable SEM, which allows the simultaneous analysis of a series of structural equations. These methods are specifically useful when a dependent variable in one equation becomes an independent variable in another equation [15].

The use of PLS, despite its inherent limitations (particularly that it is a limited-information technique, aimed to maximize prediction, rather than fit), proves to be a way in which statistical modeling in management accounting can progress without the need of large samples, something which management accounting researchers have found challenging. Another advantage of PLS is the technique's ability to accommodate non-normal data, caused by less challenging assumptions [16].

The "PLS approach" concept is fairly large and combines PLS for path models and PLS regressions. Seizing a recommendation by Martens [17], this paper uses the term PLS for Structural Equation Modeling to describe the use of "PLS Path Modeling" as illustrated in Fig. 1.

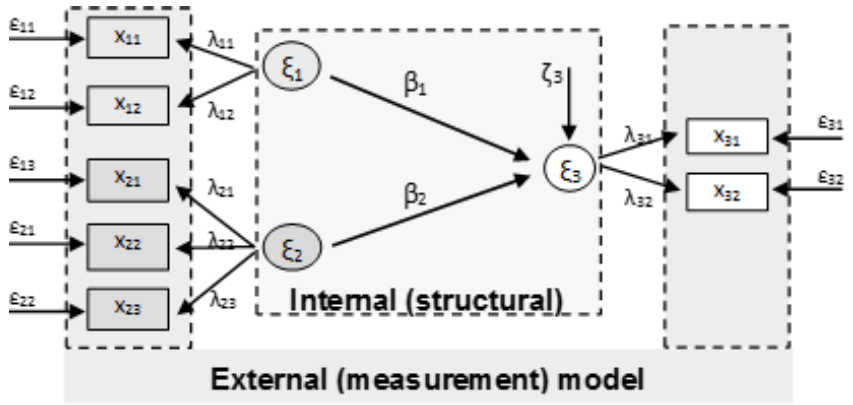

Fig. 1. Illustration of PLS path modeling example.

The internal (or structural) model describes the causality between the latent variables. A latent variable is called exogenous if it is only affecting other variables (basically any variable from which arrows only emanate). Any variable that regresses on another variable is defined to be an endogenous variable (any variable receiving an arrow). Each endogenous latent variable in a structural model is linked to other latent variables using the following multiple regressions:

$$
\xi_{k}=\beta_{0 k}+\sum_{k=1}^{K} l_{k k^{\prime}} \beta_{k k^{\prime}} \xi_{k^{\prime}}+\zeta_{k}
$$

where $\beta_{k k^{\prime}}$ (path coefficient or correlation index) expresses the impact of exogenous latent variables on endogenous latent variable $\xi_{k}$. The only assumption of this model is that residual vector $\zeta_{k}$ has a mean of zero and is uncorrelated with the predictors [18]. The only constraint of the structural model is to not have a loop in the model, which is the main feature in the so-called recursive models.

The external (or measurement) model connects the manifest variables to their own latent variable. The latent variable is the common cause shared by all the manifest variables that can be formalized by a simple regression. In other words, the latent variable exists only theoretically but cannot be observed. It influences the indicators, explaining their inter-correlations. There is therefore a first set of equations linking the manifest variables of the latent endogenous variables $(x)$ to their associated measurement errors $(\varepsilon)$ and to the exogenous latent variables.

$$
\begin{gathered}
x_{k i}=\lambda_{0 k}+\lambda_{k i} \xi_{k}+\varepsilon_{k i} \\
k=1 \ldots k \text { and } i=1 \ldots p_{k}
\end{gathered}
$$

where $x_{k i}$ represents the manifest variable $i$ of the block $k$, $\lambda_{k i}$ the loading associated with the manifest variable $i$ of the block $k, k$ the number of endogenous latent variables, $p_{k}$ the number of manifest variables of the $k$ block and, finally, $\varepsilon_{k i}$ the error value of the $i$ variable from the $k$ block. The assumption behind this model is that the residues $\varepsilon_{k i}$ have a zero mean and is uncorrelated with the latent variable of the same block [19].

Finally, even if newer and more complex PLS programs are available today (e.g. PLS-Graph or Smart PLS), a better analysis and continuous understanding of the PLS Path Modeling allowed us to develop our own software from scratch (PLS Assistant). The objective was to combine all statistical methods we are using in one single and reliable tool: 
compute the principal component analysis (PCA), estimate the path weighting scheme and, finally, generate bootstrap validation procedure and assess the best model from all possible graphs [8].

\section{DATA AND Methodology}

There are five main successive steps at the end of which will allow the construction and implementation of the OBSC: 1) collect historical data from the organization, 2) filter and prepare the final database, 3) identify the numbers of strategic perspectives and establish the performance indicators connected to the strategic perspectives, 4) generate the optimal cause-and-effect link between all strategic perspectives and, finally, 5) operate the OBSC for long-term planning [14].

The proposed methodology presented in this paper, although universally applicable to any type of organization, is exemplified in a Swiss health institution. Comprising in total eight Geneva public hospitals, the institution is positioned as a global reference, being in the 49th place in international rankings and the 3rd in Europe. However, the environment in which the hospitals are acting is constantly facing multiple demands: quality development, patient experience improvement (perceived quality), national or international certifications, safety enhancement, costs management and professional shortness. It is under this context that in 2007, the institution starts implementing a BSC, as per Kaplan and Norton methodology. Nevertheless, as presented in the literature review section, the organization encountered major roadblocks in the actual management of the tool. Furthermore, as the institution had a major strategy restructure in 2012, the initial BSC became obsolete and the executives started to look for alternatives. Below is a clear explanation of the OBSC methodology that was implemented in two of hospital's major departments (Pediatric and Gynecology/Obstetrics).

\section{Step 1: Collecting the Data}

The first step in building an OBSC is gathering of all historic key performance metrics all over the company. This first step is essential and will significantly influence the following steps. Although this seems a simple task, it actually involves a substantial time collecting the measures used in the company, especially building a valid historic database [3] It is also important that the key metrics describe to a certain extent the strategy of the organization. Undeniably, the performance indicators differ among organizations, especially among different sectors and areas (e.g. profit vs. non-profit, private vs. public, etc.).

Applying above step in our Swiss health institution resulted in a total of 92 variables for the Pediatrics department and 90 variables for the Gynecology/Obstetrics department, summarizing their evolution over 6.5 years on a monthly basis (77 periods to be more precise). The main advantage was that the organization uses a type of management software that allows supplying all kinds of historic data related to its activities and thus the collection of the data was straightforward. The variables have been gathered from different strategic areas: Financial, Internal and External Quality, Human Resources and Internal
Processes. All data has been collected with the assistance of the Corporate Strategy Head certifying high quality and reliable data.

\section{Step 2: Cleaning the Data}

Considering the significant number of indicators, the second step is a final cleaning of the database (Table I). As mentioned in previous step, the database preparation is fundamental as the collected variables could contain errors and might pollute the findings. Consequently, the variables should be characterized by 1) reliability and consistency, 2) same incidence in time, 3 ) ability to capture a fraction of the organizational strategy, 4) information singularity and 5) clarity and straightforwardness [14]. This second step is realized through consistent analysis and intense top management discussions and will ensure that the retained variables are the essential drivers for the organization.

TABLE I: EXAMPLE OF KEY PERFORMANCE INDICATORS DATABASE

\begin{tabular}{cccccc}
\hline \hline Periods & Ind 1.1 & Ind 1.2 & Ind 1.3 & $\cdots$ & Ind z.y \\
\hline Period 1 & $x$ & $x$ & $x$ & $\cdots$ & $x$ \\
\hline Period 2 & $x$ & $x$ & $x$ & & $x$ \\
\hline Period 3 & $x$ & $x$ & $x x x$ & & $x$ \\
\hline$\ldots$ & $x$ & $x$ & & $x$ \\
\hline Period n & \multicolumn{1}{c}{$\begin{array}{c}\text { Missing } \\
\text { variables }\end{array}$} & $x$ & $x$ & $\cdots$ & $x$ \\
\hline \hline & & & $\begin{array}{l}\text { Unreliable } \\
\text { variable }\end{array}$ & \\
\end{tabular}

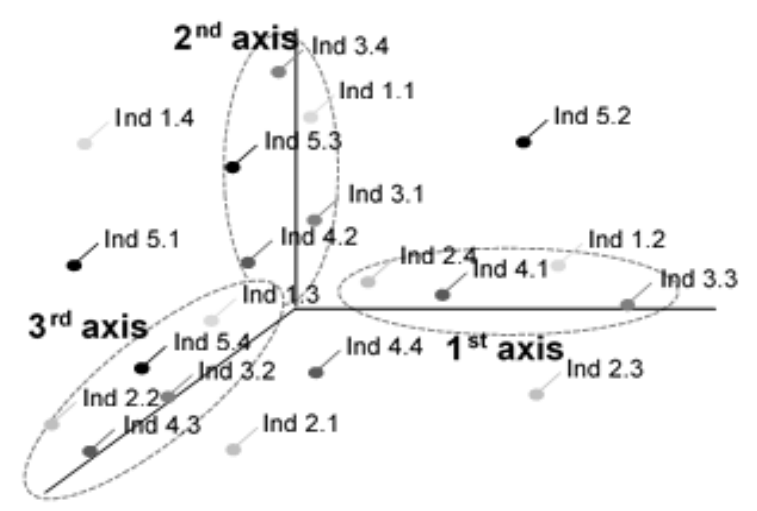

Fig. 2. Filtering the performance indicators per strategic perspectives.

Due to missing variables and a lot of duplications between indicator values, only a total of total of 40 key performance indicators have been retained in the final database out of a total of 182 variables.

\section{Step 3: Cleaning the Data}

Although previous step allowed us to keep only the information that is the most crucial, the organization continues to have an amalgam series of KPI database, still difficult to categorize for the BSC construction. As showed in Fig. 2, the third main step is to filter and group the variables within specific axes (or strategic perspectives) able to summarize a part of the company's performance.

There are three main objectives in performing this step: first is to identify the number of strategic axes summarizingan acceptable level of the total organization's performance, second is to filter each axis and select only the key indicators that are highly correlated, disregarding any redundant and unsuitable information and, third is to label 
these groups of indicators by studying the nature of information that gravitates each strategic perspective [14].

As Morard, Stancu and Jeannette mentioned in one of their articles back in 2009, there are several existing statistical techniques capable to complete this step [3]. Both factor analysis and principal component analysis (PCA) can be used for clustering. Principal component analysis can be employed for dimensionality reduction in a series of data by preserving those characteristics that influence most its variance and by maintaining lower-order principal components and disregarding higher-order ones. As such, the PCA suits better our study requirement, as it is matching a non-predefined experimental model, while factor analysis is fitter for models that already have a standard. As the statistical method (i.e. PCA) is treating historical data, the final results will therefore be dependent on the data available at the time of compendium. Nevertheless, the intention of our research is not to develop the best indicators, which sometimes could be governed by subjectivity and personal preference, but to highlight the importance of the performance indicators already existing [3].

Implementing the PCA on all the selected 40 KPIs from the Swiss health institution, one can notice that with four components a total of $79 \%$ of the total organizational variance is explained (Table II). This percentage can be explained as the influence of the axes on the total performance: the higher this percentage, the more explanation it provides on the company's performance.

TABLE II: EXTRACT OF TOTAL VARIANCE EXPLAINED

\begin{tabular}{ccc}
\hline \hline Component & \% of Variance & Cumulative \% \\
\hline \hline 1 & 43.51 & 43.51 \\
\hline 2 & 24.39 & 67.90 \\
\hline 3 & 6.08 & 73.97 \\
\hline $\mathbf{4}$ & $\mathbf{5 . 4 8}$ & $\mathbf{7 9 . 4 5}$ \\
\hline \hline
\end{tabular}

The same PCA provides the impact of the variables (or indicators) against each of these four axes with the help of the component matrix that establishes the correlation of all variables with each of these axes. Table III exemplifies the correlation of the first 10 normalized variables with each axis The closer a correlation is to zero, the less the corresponding variable affects the axis. Finally, the variables will be filtered and ordered in function of the correlations with the axes.

One may observe that a simple mathematical grouping will identify the strategic areas specific to the organization. Nevertheless, even though statistically speaking the highest ranked indicators are strongly correlated to the respective axis, one still need to do a thorough analysis of the data and clear out and/or replace those variables that would not effectively support the definition of the strategic perspective. While this practice it is not mathematically validated, it is primarily intended to remove certain indicators that would violate the definition of the axis and might corrupt the final results [3]. The ranking and clustering of variables by axis will allow us to label and define them strategically.

At the end of this third step, the organizational strategy from the Swiss hospital was acknowledged to congregate along four main perspectives: 1) Employee Development \& Commitment, 2) Finance, 3) Organizational Processes and, finally, 4) Patient Satisfaction.

TABLE III: EXTRACT OF THE FIRST 10 INDICATORS FROM COMPONENT MATRIX (NORMALIZED)

\begin{tabular}{ccccc}
\hline \hline VAR name & $\mathbf{1}^{\text {st }}$ axis & $\mathbf{2}^{\text {nd }}$ axis & $\mathbf{3}^{\text {rd }}$ axis & $\mathbf{4}^{\text {th }}$ axis \\
\hline Other operating costs & 0.563 & 0.774 & 0.027 & 0.016 \\
\hline Rate of falls & 0.006 & 0.012 & 0.705 & 0.056 \\
\hline Billing rates of drugs & 0.398 & 0.197 & 0.083 & 0.621 \\
\hline Yield of staff costs & 0.505 & -0.081 & 0.151 & 0.721 \\
\hline Total DRG billed items & 0.808 & 0.564 & 0.050 & -0.034 \\
\hline Total OFAS billed items & 0.702 & 0.408 & -0.119 & -0.148 \\
\hline Average billed costweight & 0.497 & -0.143 & -0.266 & 0.617 \\
\hline Financial result & 0.206 & 0.066 & 0.545 & 0.428 \\
\hline Total revenue & 0.904 & 0.144 & -0.082 & -0.105 \\
\hline Hospital revenue & 0.917 & 0.114 & -0.061 & -0.102 \\
\hline \hline
\end{tabular}

\section{Step 4: Finding the Optimal Balanced Scorecard}

The fourth major step in mapping the actual strategy of the organization is to apply the PLS Path Modeling regression on the strategic perspectives agreed on previous step. To determine the optimal cause-and-effect chain, we will examine all possible valid combinations between the strategic perspectives. The most stable PLS model from all possible arrangements is considered the closest to the organization's current strategy [14]. The stability of the model could be selected using the bootstrap quality criterion [3], [8], [20].

\section{Step 5: Forecasting Company's Strategy}

As mentioned in the beginning of this study, the inner and outer connections from any PLS model are founded on structural equations. Accordingly, these equations explain the relationships between indicators and the corresponding perspective (outer model equations) and between the strategic perspectives themselves (inner model equations). The fifth and final essential step is based on using these equations in order to study and predict the relationships on the long run [21]. From a practical point of view, there are noteworthy benefits in completing this final step: 1) analyze the impact of one (or several) changes in the indicators to the whole model; 2) forecast the strategic changes needed by studying the relations between the strategic perspectives; 3) visualize and manage the direct and indirect changes required for an important shift in the organization's strategy; 4) simulate the impact of resources allocation on the future performance and strategy.

\section{Results AND Model Validation}

\section{A. Optimal Balanced Scorecard (OBSC)}

Coming back to the health institution example, after applying the subsequent steps as described above, all possible valid connections between the four perspectives were analyzed. The optimal PLS model has been constructed and selected using our educational software (PLS Assistant) developed and programmed from scratch based on the original PLS Path Modeling algorithm. Fig. 3 illustrates the optimal structure of connections between the four strategic perspectives and turns out to be more representative than any other model, being the closest representative of the current organizational strategy.

As one can notice, the two main pillars of this health 
institution are the Patient Satisfaction and the Organizational Processes which are contributing to the financial area. The Patient Satisfaction has another contribution to the Employee Commitment. It is indeed very interesting to observe that the patient is driving the internal commitment and not the other way around. This signifies that this organization is acting on behalf of their patients and more these are satisfied, the more employees are dedicated and eager to improve. A second observation is related to the financial perspective that is the ultimate goal of the organization. This is not necessary unhealthy, but it is not in line with the hospital ethics (finance should be seen as a base of development, but not as an objective), [24], [25]. This idea was already acknowledged by the top management and they are currently looking into measures to adjust and refine their strategy to a more sustainable health institution.

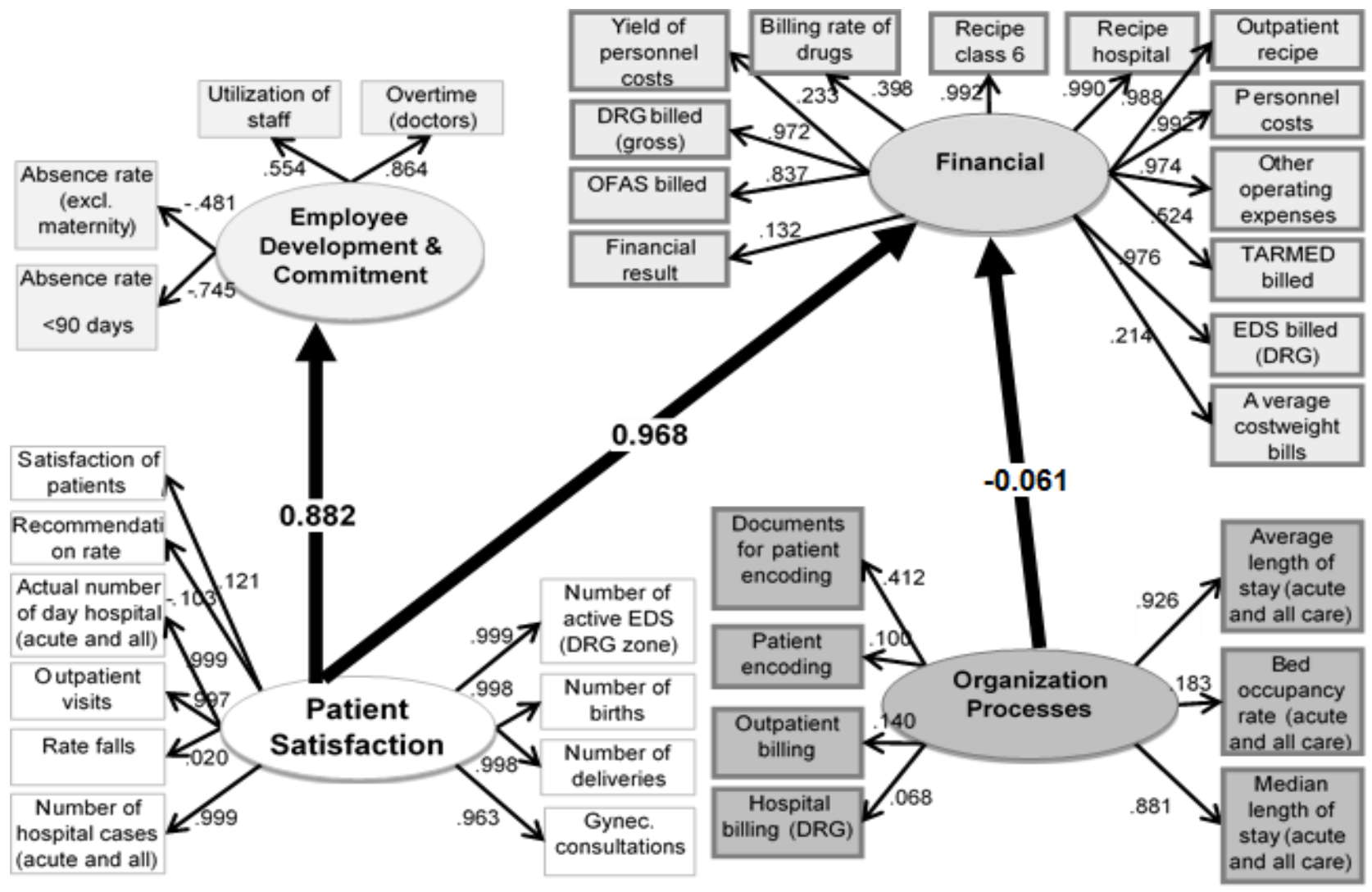

Fig. 3. OBSC's cause-and-effect map using PLS path modeling.

When it comes to model validation from a statistical perspective (Table IV), the validation figures are endorsing very well both measurement (outer) and structural (inner) model. As a general rule of thumb, in order to validate the outer model (measurement model), the Average Variance Extracted (AVE) should be greater than 0.5 (Chin, 1998) and Composite reliability higher than 0.6 [22], [23]. Composite reliability is like the reliability of a summated scale and AVE is the variance in the indicators explained by the common factor. As one can notice, all values are above the minimal threshold and they confirm that this is a stable PLS model.

As for structural (inner) model validation, the best indicator to use is the R-square level. Values of $0.67,0.33$ and 0.19 are considered to be strong, moderate and respectively weak for the inner model valuation [22]. The $\mathrm{R}$-square have all strong values for the perspectives that are impacted in the final model which proves a pretty stable model.

\section{B. Kaplan and Norton's Balanced Scorecard}

As the strategic perspectives corresponded in our case to the Kaplan and Norton methodology, we were able to map the cause and effect chain for this BSC and compare to our previous OBSC results. Fig. 4 is illustrating the BSC as per Kaplan and Norton's approach.
Applying the PLS regression to the Kaplan and Norton's BSC model, one can notice that the validation figures are definitely below the acceptable threshold and they do not represent the actual organization in any way, therefore the organization's strategy is not properly reflected. Above model is lacking any consistency and it is not assist the executives in taking the right decision for the good future of the organization. As we have mentioned in previous researches, the Kaplan and Norton's BSC in only a subsequent result of our methodology, and is too flawed to be selected as the optimal model from all possible combinations between strategic perspectives.

As one can notice from the model validation Table V, the Kaplan and Norton's BSC has lower AVE and R-Square values, even below the agreed threshold.

TABLE IV: PLS MODEL VALIDATION CRITERIA FOR OBSC

\begin{tabular}{cccc}
\hline \hline & AVE & $\begin{array}{c}\text { Composite } \\
\text { reliability }\end{array}$ & R-Square \\
\hline Finance & 0.617 & 0.945 & 0.980 \\
\hline Organizational Processes & 0.520 & 0.851 & \\
\hline Patient Satisfaction & 0.744 & 0.963 & 0.779 \\
\hline $\begin{array}{c}\text { Employee Development } \\
\text { and Commitment }\end{array}$ & 0.560 & 0.617 & \\
\hline \hline
\end{tabular}




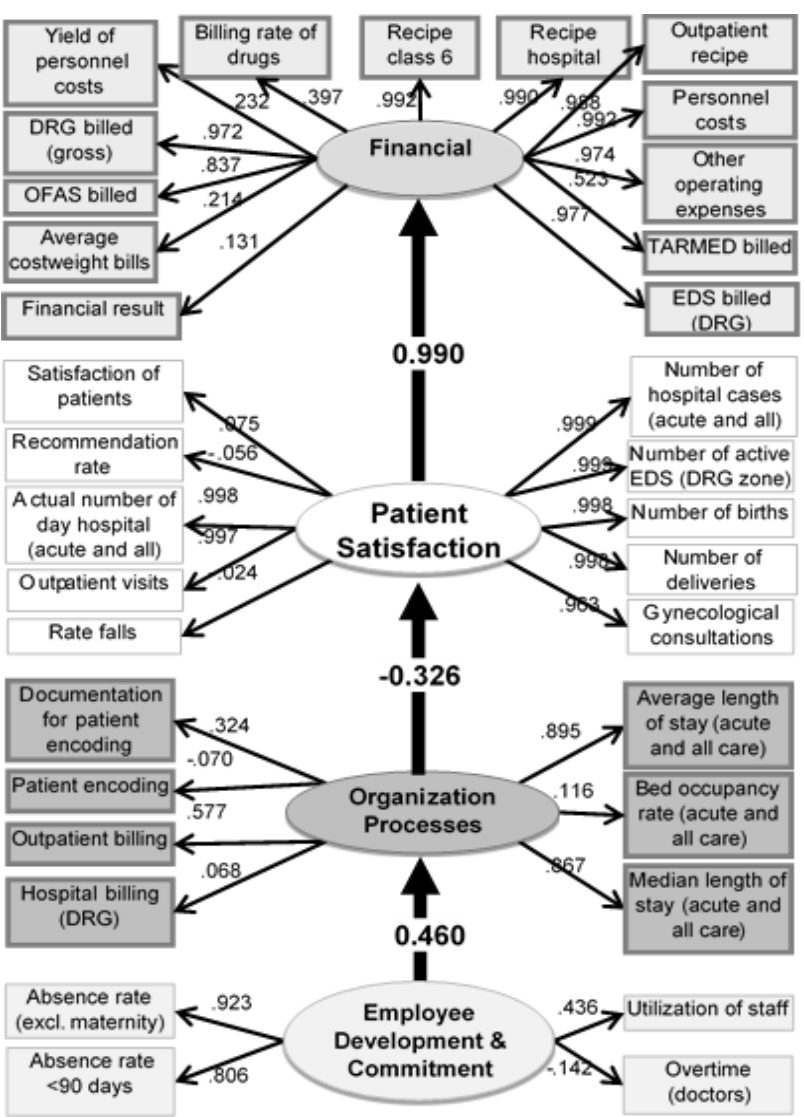

Fig. 4. Kaplan and Norton's BSC cause-and-effect map using PLS path modeling.

TABLE V: PLS VALIDATION CRITERIA FOR KAPLAN AND NORTON'S BSC

\begin{tabular}{cccc}
\hline \hline & AVE & $\begin{array}{c}\text { Composite } \\
\text { reliability }\end{array}$ & R-Square \\
\hline Finance & 0.582 & 0.940 & 0.977 \\
\hline Organizational Processes & $\mathbf{0 . 3 9 6}$ & 0.822 & $\mathbf{0 . 2 1 1}$ \\
\hline Patient Satisfaction & 0.742 & 0.963 & $\mathbf{0 . 1 0 7}$ \\
\hline $\begin{array}{c}\text { Employee Development } \\
\text { and Commitment }\end{array}$ & $\mathbf{0 . 4 3 8}$ & 0.641 & \\
\hline \hline
\end{tabular}

\section{CONCLUSION}

The main purpose of this paper was to compare the Kaplan and Norton BSC theory with a more pragmatic approach. Having defined the strategic research framework, we empirically validate the proposed methodology by developing a strategic map in the context of a Swiss hospital. The results obtained indicated that the BSC issues could be formalized in a more rigorous manner. It is therefore possible to reconsider the notions put forward by Kaplan and Norton as showed in the analysis of this case.

The application of PLS Path Modeling translates the actual strategy of any company into a cause-and-effect model that can be monitored and controlled using a handful of key performance indicators. One might argue that by treating historical data, the model summarizes outdated information by illustrating a picture that might not be exploited to predict future planning. While this supposition is legitimate, the methodology is actually identifying the current strategy applied by the organization. Only by fully recognition of the actual situation one can plan for the period to come. As mentioned in this study, the PLS regression is more suitable for maximizing prediction, thus the model is capable of disclosing the forecast strategy of the company. Moreover, this approach can simulate the impact of resource allocation impact on the organization's overall performance.

To conclude, we believe that it is important to progress a more formal and rational methodology in order to validate the organization's strategy, while using a simplified model. Indeed the PLS method suffers from a deficiency of theoretical foundation. But similarly, Kaplan and Norton's approach was also criticized in the specialized literature from this point of view. The difficulty with which future researchers will be challenged lies in the compromise between the pragmatism required by the organizations and the need for a more theoretical framework requested by researchers.

\section{REFERENCES}

[1] W. W. Chin, "The Partial Least Squares Approach to Structural Equation Modeling," Modern Methods for Business Research, 1998, pp. 295-336.

[2] T. Fielden, "Pilot Refines Decision Support," InfoWorld, 1999, November 29, pp. 77-78.

[3] J. F. J. Hair, R. E. Anderson, R. L. Tatham, and W. C. Black, Multivariate data analysis with readings, 5 ed., Upper Saddle River, NJ: Prentice-Hall International, 1998.

[4] G. K. Kanji and P. Moura, "Kanji's business scorecard," Total Quality Management, vol. 13, no. 1, 2002.

[5] S. R. Kaplan and P. D. Norton, "Putting the balanced scorecard to work," Harvard Business Review, September - October, pp. 142-143, 1993.

[6] S. R. Kaplan and P. D. Norton, "Using the balanced scorecard as a strategic management system," Harvard Business Review, January February, pp. 75-85, 1996.

[7] S. R. Kaplan and P. D. Norton, "Linking the balanced scorecard to strategy," California Management Review, fall, pp. 53-79, 1996.

[8] A. M. Malina and H. F. Selto, Causality in Performance Measurement Models, November, 2003.

[9] H. Martens, "Domino PLS: A framework for multi-directional path modeling" in PLS and Related Methods, T. Aluja, J. Casanovas, V. Esposito Vinzi, A. Morineau, and M. Tenenhaus, Eds. Barcelona, 2006, pp. 125-132.

[10] B. Morard, A. Stancu, and C. Jeannette, "Finding your company's optimal balanced scorecard: a new quality criterion," Economics and Finance Research, vol. 61, pp. 64-74, 2013.

[11] B. Morard, A. Stancu, and C. Jeannette, "Time evolution analysis and forecast of key performance indicators in a balanced scorecard," Global Journal of Business Research, vol. 7, no. 2, pp. 9-27, 2013.

[12] B. Morard, A. Stancu, and C. Jeannette, "The relationship between structural equation modeling and balanced scorecard: evidence from a swiss non-profit organization," Review of Business and Finance Case Studies, vol. 3, no. 2, pp. 21-37, 2012.

[13] B. Morard, A. Stancu, C. Jeannette, and E. Hamoir, "Quasi-analytical definition of a practical balanced scorecard: a building process approach," International Journal of Business, Marketing, and Decision Sciences, vol. 2, no. 1, pp. 39-58, 2009.

[14] B. Morard and A. Stancu, "Structural Equation Modeling in a Rationalization Tentative of Balanced Scorecard," Cahiers de Recherche, University of Geneva, September 2005.

[15] H. Nørreklit, "The balance on the balanced scorecard - a critical analysis of some of its assumptions," Management Accounting Review, vol. $11,2000$.

[16] C. C. Pineno, "The balanced scorecard: an incremental approach model to health care management," Journal of Health Care Finance, 2002

[17] S. Silk, "Automating the balanced scorecard," Management Accounting, no. 38-40, pp. 42-44, May 1998.

[18] M. Shields, "Research in management accounting by North American in the 1990's," Journal of Management Accounting Research, vol. 9, pp. 1-61, 1997.

[19] J. F. Shields and M. Shields, "Antecedents of participative budgeting," Accounting, Organizations and Society, vol. 23, pp. 49-76, 1998.

[20] D. Smith and L. K. Smith, "Structural equation modeling in management accounting research: critical analysis and opportunities," Journal of Accounting Literature, vol. 23, pp. 49-86, 2004.

[21] A. Stancu, "The rationalization of balanced scorecard using multivariate statistical approach," Dissertation submitted in fulfillment 
of Doctor's Degree in Management at the Faculty of Economic and Social Sciences, University of Geneva, 2009.

[22] C. E. Werts, R. L. Linn, and K. G. Joreskog, "Interclass reliability estimates: testing structural assumptions," Education and Psychological Measurement, vol. 34, pp. 25-33, 1974.

[23] H. Wold, "Path Models with Latent Variables: The NIPALS Approach," in Quantitative Sociology: International Perspectives on Mathematical and Statistical Modeling, H. M. Blalock, A. Aganbegian, F. M. Borodkin, R. Boudon, and V. Cappecchi, Eds. New York: Academic Press, 1975, pp. 307-357.

[24] H. Wold, "Partial least squares," Encyclopedia of Statistical Sciences, New York: Wiley, 1986, vol. 6.

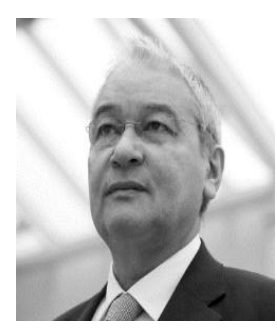

Bernard Morard is a double Ph.D in both finance and management accounting. He is born on August 6, 1956 in France. He specialized his knowledge in the financial and management accounting field by teaching in prestigious schools like the University of Law, Faculty of Applied Economics in Aix-en-Provence, then the University of Montréal. He is also the author of numerous publications in the specialized field. Since 1990; he is full professor at the University

of Geneva, Switzerland.

After being the president of the HEC business school, he was elected in 2009 the Dean of the Faculty of Social and Economic Sciences at the University of Geneva. Using his entrepreneurial approach, Bernard created in the last decade more that 30 economic programs for professionals in various sectors. His two PhDs made him very polyvalent on the research side, his fields of research being focused on specific statistical tools for a better understanding of the performance, both in a macro and micro sector His favorite computational tools are Matlab, SPSS, Mathematica and Free Basic.

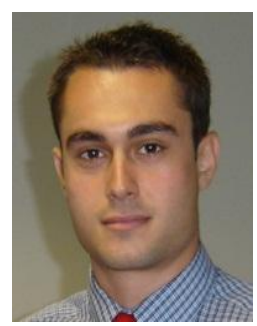

Alexandru Stancu is a Romanian nationality, born January 6, 1981. He finalized his Ph.D in 2009 in Economics at University of Geneva, Switzerland, focusing on the Balanced Scorecard concept and identifying new ways of rationalizing the organization's strategy designing a more realistic management tool. He based his research and methodology on multiple regression statistical methods such as principal component analysis (PCA) and partial least squares (PLS). Alexandru is currently working in IATA (International Air Transport Association),
Geneva, Switzerland, where he holds a business performance manager position in the Corporate Planning department since 2011. In his previous job, he worked at the University of Geneva, Switzerland as teaching and research assistant while completing his $\mathrm{PhD}$ studies.

Alexandru is the author of several publications in the field of management, accounting and he continues to publish on a regular basis. Major publishing achievements are: "Finding your Company's Optimal Balanced Scorecard:

A New Quality Criterion," Economics and Finance Research II, IPEDR vol. 61, 2013; "Time Evolution Analysis and Forecast of Key Performance Indicators in a Balanced Scorecard," Global Journal of Business Research, vol. 7, no. 2, 2013; "The Relationship between Structural Equation Modeling and Balanced Scorecard: Evidence from a Swiss Non-Profit Organization," Review of Business and Finance Case Studies, vol. 3, no. 2, 2012; amongst many others. His current research interests are based on refining the Balanced Scorecard methodology and forecasting capabilities of PLS

Alexandru became a Senior Member (M) of IEDRC in 2013. He participated and was awarded numerous times at various international conferences in USA (Orlando and Hawaii), China (Macau), Japan (Osaka), Costa Rica (San Jose), France (Marseille) and Italy (Milan).

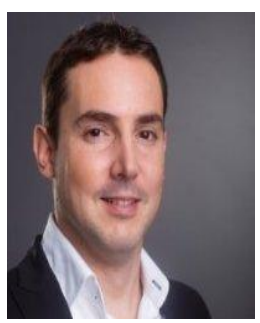

Christophe Jeannette is a research assistan finishing his Ph.D in economics. He is of France nationality, born October 19, 1980 in Nice, France. After a license degree in mathematics and computer science in Toulouse, France, Christophe is currently a teaching and research assistant in management accounting at the University of Geneva, Switzerland. $\mathrm{He}$ is in process of finalizing his $\mathrm{PhD}$ thesis identifying and establishing patterns for a company's failure and bankruptcy processes. Using specific statistical tools, he managed to find new ways for a better understanding of what defines performance within a company in order to generalize it at a larger scale of different industry sectors. Pushing forward these results, he is now working on a way to assist the decision making process by creating new forecasting tools. There search pursued allowed him to publish several scientific articles in this relatively new scientific field Christophe is in the full developer of PLS software (PLS assistant) that enabled many in-house studies and researches to be analyzed and finalized. 